\title{
Proteomic Complex Detection using Sedimentation (ProCoDeS)
}

\author{
Nicholas T. Hartman, Kathryn Lilley and Paul Dupree* \\ Department of Biochemistry, University of Cambridge, Building O, Downing Site, \\ Cambridge CB2 1QW, UK
}

Two spreadsheets and a supplementary figure.

Supplementary Table 1: Results for protein identification and quantitation from the $6.25 \mathrm{hr}$ RZG experiment.

Supplementary Table 2: Results for protein identification and quantitation from the $7.50 \mathrm{hr}$ RZG experiment.

Supplementary Figure 1: SDS-PAGE analysis of RZG fractions. 